This is the second specimen record for Saskatchewan for the Pomarine Jaeger; the first from Yellow Grass on November 9, 1922, ${ }^{2}$. There are also sight records from Kazan Lake by T. E. Randall and from Torch River by $C$. Stuart Francis. ${ }^{3}{ }^{1}$.

'FRANCIS, C. S. 1946. A list of the birds of Nipawin, Saskatchewan. Mimeographed July, 1943. Blue Jay 4:45.
${ }^{2}$ MITCHELL, H. H. 1924. Birds of Saskatchewan. Canadian Field-Nat. 38:101. 118.

${ }^{3}$ RANDALL, T. E. 1962. Birds of the Kazan Lake region, Saskatchewan. Blue Jay 20:60-72.

${ }^{4}$ RIDGWAY, ROBERT. 1919. The birds o North and Middle America: A de. scriptive catalogue. Vol. 8 Gov't. Print ing office Washington, D.C. 852 pp.

\title{
WHITE RING-BILLED GULL AT SASKATOON
}

\section{J. B. GOLLOP, 2202 York Avenue, Saskatoon, Saskatchewan S7J 1J1}

On July 14, 1977, R. C. Godwin reported a white gull on the lawn west of the Prairie Migratory Bird Research Centre, University Campus, Saskatoon. The bird was later studied with binoculars and photographed at distances of 50 to 150 meters for about 35 minutes by John Hanbidge and the author.

Most of the time, the plumage appeared to be pure white, even through binoculars, but at the right angle in full sun the back and wings were a very pale blue. The bill and legs were the same yellowish colour as nearby normal Ring-bills but the ring on the bill was washed out - a pale gray. The eye appeared dark. The wing tips and upper tail were white a observed when the bird was walkin and flying. The bill, head and bod appeared to be the same size as the smallest normal Ring-bill but wer noticeably smaller than four othe adults.

While the bird fed like other gulls it usually stayed away from the nor mally plumaged birds. It flew off $b$ itself about 0530 .

What was apparently the same bir was on the same lawn with up to 19 Ring-billed Gulls on August 4, 31 an September 1 (the date of writing).

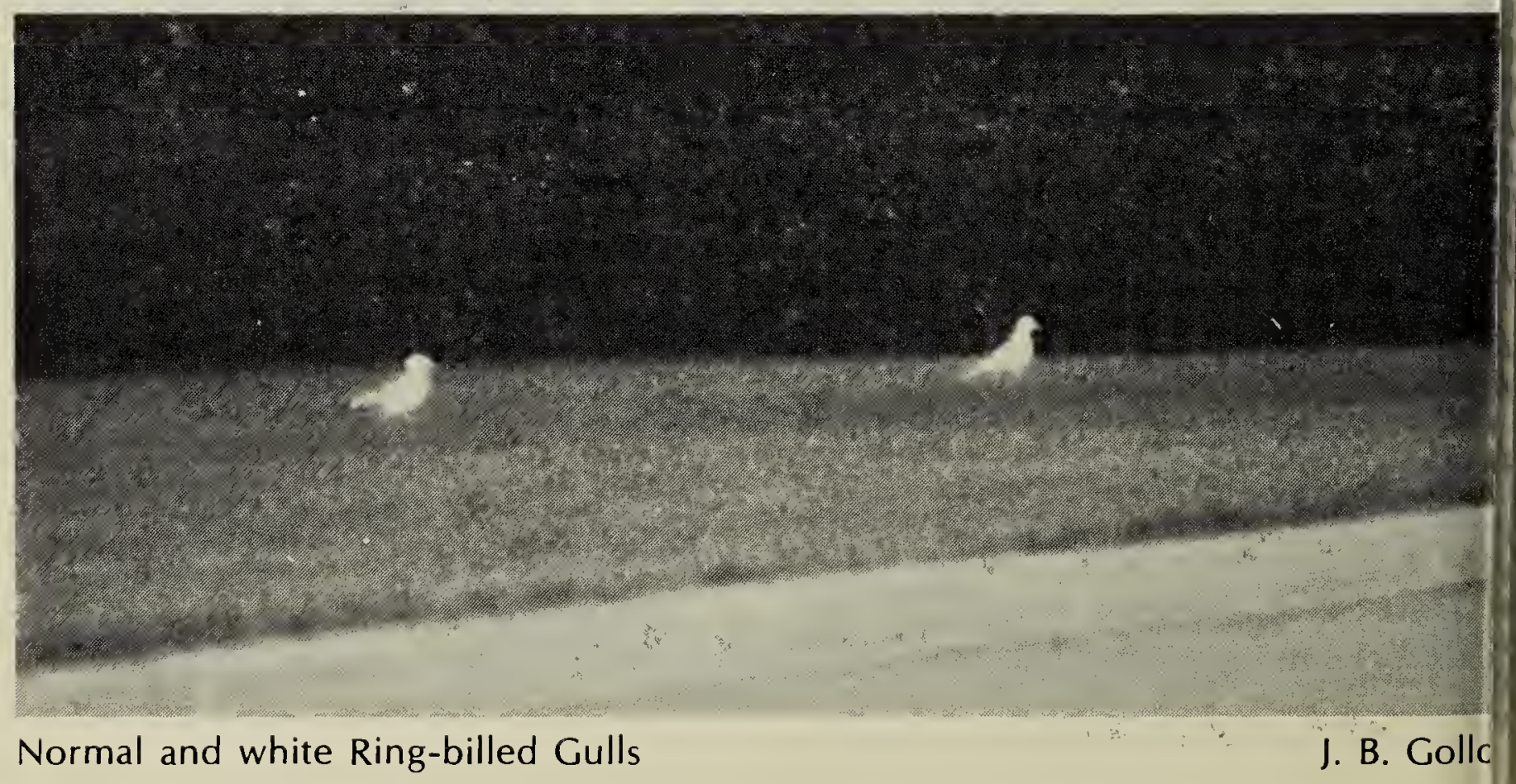

